\title{
Kota Tua Sebagai Destinasi Wisata Kota: Kenapa Tidak (Implementasi Kebijakan Publik)
}

\author{
Aang Afandi 1)*, Dewi Rahayu ${ }^{2)}$ \\ 1) Jurusan Akuntansi, Politeknik Negeri Malang, J1. Soekarno Hatta No 9, Malang, 65141, Indonesia \\ 2) Jurusan Ilmu Ekonomi, Universitas Lambung Mangkurat, Jl. Brigjend H. Hasan Basry, Indonesia \\ E-mail corresponding author: aang.afandi@polinema.ac.id
}

Received: 31-01-2021;

Accepted: 08-04-2021;

Available online: 30-04-2021

Ecoplan Vol. 4 No. 1, April 2021, hlm 10-20.

\section{ISSN p: 2620-6102 e: $2615-5575$}

Abstract - Cities in Indonesia continue to improve, both physically and non-physically, to become smart cities. This is also the function of the city as the center of activity in a region. On the other hand, some cities have a history with their old cities. This old city asset deserves to be maintained, preserved, and developed as a city tourism destination. This study aims to identify how a city that has old city assets can manage its assets as a city tourist destination, then to identify the potential of cities in Indonesia and to make stages that the city must carry out if it wants to utilize the assets of the old city as a city tourist destination. The study method used is to explore the city in the management of the old town area so that it can get a picture of what is being done by comparing it to several other cities in the world and related to the prerequisites of a destination as city tourism. The results show the stages that can be used as a reference for the city to develop the old city. The results of this study need further deepening, related to the recommended stages and the need for Delphi methods, as a form of FGD with experts in their fields where this activity is indeed multi-scientific background. So that the governance of material and intangible cultural heritage can be achieved without neglecting the various values that must be fulfilled. It is hoped that this phasing can serve as a raw model in the management of the old town (cultural heritage) in other cities.

Abstrak - Kota - kota di Indonesia terus berbenah, baik fisik maupun non fisik, untuk menjadi smart city. Hal itu sekaligus sebagai fungsi kota sebagai pusat aktivitas suatu wilayah. Disisi lain, beberapa kota yang memiliki sejarah dengan keberadaan kota tuanya. Aset kota tua inilah sebenarnya layak untuk dipertahankan, dilestarikan dan memungkinkan dikembangkan sebagai destinasi pariwisata kota. Kajian ini bertujuan untuk mengidentifikasi bagaimana sebuah kota yang memiliki aset kota tua mampu mengelola aset nya sebagai destinasi wisata kota, berikutnya mengidentifikasi potensi kota - kota di Indonesia dan Menyusun pentahapan yang mesti dilakukan oleh kota bila ingin memanfaatkan aset kota tua sebagai destinasi wisata kota. Metode kajian yang digunakan adalah berupaya mengeksplorasi kota dalam tata Kelola Kawasan kota tua sehingga memperoleh gambaran tentang apa yang dilakukan dengan komparasi pada beberapa kota lain di dunia dan dikaitkan pula dengan prasyarat destinasi sebagai pariwisata kota. Hasilnya menunjukkan pada pentahapan yang secara umum dapat dijadikan acuan bagi kota untuk mengembangkan kota tua. Hasil penelitian ini perlu pendalaman lebih lanjut, berkaitan dengan pentahapan yang direkomendasikan dan perlu adanya delphi methods, sebagai bentuk FGD dengan para ahli dibidangnya yang mana aktivitas ini memang multi latar belakang bidang keilmuan. Sehingga tata Kelola cagar budaya benda dan tak benda dapat tercapai, tanpa mengabaikan berbagai nilai - nilai yang mesti 
dipenuhi. Harapannya pentahapan ini dapat sebagai raw model dalam pengelolaan kota tua (cagar budaya) di Kota - Kota yang lain.

Kata Kunci: Kota Tua, Pariwisata Kota, aset benda dan tak benda

\section{PENDAHULUAN \\ Latar Belakang}

Berbagai kota di Indonesia terus berbenah, baik pengembangan dan pembangunan fisik maupun aktivitas non fisik. Sehingga harapannya menjadi smart city, yang warga kotanya semakin nyaman dengan tempat tinggalnya. Termasuk memenuhi masyarakat lain yang membutuhkan aktivitas di Kota. Sementara itu, terdapat beberapa kota di Indonesia yang memiliki kota tua dengan aset bangunan - bangunan tersisa dan warisan tak benda yang tersisa atau bahkan masih terjaga di kalangan masyarakat lokal. Tentunya aset cagar budaya benda dan tak benda perlu dilestarikan sebagai fungsi menjalankan pelestarian cagar budaya. Selain itu juga berpeluang untuk destinasi pariwisata kota.

Beberapa kota masih mengabaikan aset cagar budaya ini, sementara ada beberapa kota yang mulai merevitalisasi dan memanfaatkannya. Bisa jadi di antara kota ini, cenderung ikut - ikutan dengan kota lain. Walaupun ada pula yang lebih "seriously" mengelola cagar budaya.

Pengelolaan dan pelestarian Cagar budaya ini masih menghadapi berbagai persoalan yang serius, walaupun telah ada Undang - Undang No. 11 tahun 2010 tentang Cagar Budaya, namun aturan teknisnya sampai saat ini belum tersedia. Sementara itu muncul banyak persoalan saat implementasi dilapang salah satunya adalah aturan yang saling berbenturan. Selanjutnya pengelolaan cagar budaya ini tidak hanya memerlukan peran arkeolog saja, namun semua pemangku kepentingan, termasuk masyarakat. (Indriani, 2017). Hal inilah sebenarnya yang mesti dianalisis bagaimana seharusnya hubungan dan apa saja yang dilakukan oleh para pemangku kepentingan ini.

Idealnya, dalam pengembangan Kawasan kota tua ini memerlukan pentahapan yang runtut yang mampu menghasilkan Kawasan kota tua yang memenuhi kaidah tata Kelola cagar budaya, memiliki potensi sebagai destinasi wisata, sekaligus memberikan benefit ataupun dukungan aktivitas ekonomi pada masyarakat luas. Satu hal lagi, tanpa meminggirkan masyarakat lokal yang merupakan sentral dari warisan tak benda dari Kawasan kota tua tersebut.

\section{Landasan Teori \\ Destinasi wisata}

Menurut (Seakhoa-King, 2020) menjelaskan bahwa destinasi wisata sebagai wilayah geografis dengan batas yang jelas, seperti negara atau pulau. Sehingga diterapkan pada berbagai skala, mulai dari obyek wisata individu kecil dengan luasan beberapa hektar, hingga seukuran negara atau bahkan benua. Dengan demikian maka pada destinasi pariwisata tersebut tentunya terdapat produk pariwisata. Adapun produk pariwisata bisa berupa atraksi, fasilitas dan layanan kepada wisatawan. Dengan demikian destinasi merupakan bagian dari paket wisata yang disusun sedemikian rupa, sementara itu pemaknaan dari paket wisata (package tour) adalah suatu perjalanan wisata dengan memiliki satu atau beberapa motif yang disusun sedemikian rupa dengan berbagai fasilitas yang disediakan. (Nuriata, 2014)

Berbagai destinasi wisata yang ditawarkan oleh suatu negara atau wilayah sangat beragam, mulai dari destinasi wisata alam, wisata budaya, wisata ziarah, wisata industri dan lain sebagainya.

Kota, sebagai sebuah pusat aktivitas ekonomi, sosial dan budaya pada lingkungan tertentu tentunya juga bisa menawarkan aset kota itu sebagai wisata kota.

Kota cenderung selalu dianggap sebagai tempat yang menarik bagi wisatawan untuk mendapatkan pengalaman rekreasi yang kuat. Konsepsi pariwisata perkotaan atau disebut dengan urban tourism ini sebenarnya telah terjadi pada pertengahan 1700-an Ketika bangsawan Eropa mulai berkeliling di kota - kota Eropa lainnya. Dengan adanya perluasan jaringan transportasi, munculnya tempat hiburan komersial, pembangunan hotel dan resor, taman umum, teater, menjadi bagian wisata kota ini (Dixit, 2020).

Dengan demikian, berarti setiap kota memiliki peluang yang sama untuk memanfaatkan sumber daya kotanya untuk digunakan dan sebagai aset untuk pengembangan kota sebagai kota wisata. Yang menarik bahwa kota bisa menjadi destinasi dengan multi-motivasi, artinya orang melakukan aktivitas di kota dengan beragam jenis motivasi, seperti bisnis, hiburan dan rekreasi, mengunjungi keluarga/ kerabat, Kesehatan, berbelanja ataupun yang lainnya. Dengan peluang wisata multidimensi ini sebenarnya berpeluang banyak dan beragam aset kota yang dapat dimanfaatkan. Seperti keberadaan pasar tradisional, pasar modern, factory outlet dapat dioptimalkan sebagai fungsi wisata belanja, keberadaan pusat kebugaran, Spa, Perawatan wajah dan kulit, berbagai rumah sakit dapat dikembangkan sebagai wisata Kesehatan ataupun berbagai aset lainnya. 
Dalam sejarahnya, kota ada dan berkembang sudah cukup lama, puluhan bahkan ratusan tahun. Dengan perjalanan sejarah yang Panjang ini tentunya kota memiliki bangunan - bangunan tua, yang merupakan wujud dari kota tua dimasa lalu. Kota tua ini bisa berupa bangunan - bangunan, lanskap / view kota, budaya yang berkembang, makanan khas atau wujud - wujud lainnya.

Sementara itu, jika dikaitkan dengan konsep pariwisata perkotaan yang dapat dikaitkan dengan aset kota tua yang dimiliki maka dapat dikaitkan dengan, kota wisata sejarah (tourist-historic city), merupakan konsep pariwisata perkotaan yang menjadikan sejarah sebagai daya Tarik wisatanya. Salah satu pekerjaan rumah utama yang dihadapi adalah upaya konservasi terhadap peninggalan sejarah yang dimiliki.

Kota budaya (cultural city), konsep ini juga sering diidentikkan dengan kota sejarah atau kota heritage. Namun kota budaya jauh lebih luas dibandingkan kota sejarah. Kota budaya meliputi: 1) museum dan wisata heritage, 2) distrik - distrik budaya (pecinan, kampung arab), 3) masyarakat etnis, 4) Kawasan hiburan, 5) wisata sejarah, dan 6) trail sastra, hal ini sesuai yang dikemukakan oleh (Evans dan Ricards dan Wilson, 2007). Dengan demikian wisata budaya ini berkaitan dengan tangible dan intangible aset yang dimiliki, dan yang lebih menarik lagi pada wisata budaya ini adalah interaksi dengan masyarakat dengan budaya khasnya. Dua konsep di atas sebenarnya yang saling berkaitan dengan wisata kota tua.

\section{Pengertian Kota Tua}

Dalam kamus Oxford disebutkan Kota Tua (Old Town) adalah bagian tua dari kota atau kota yang memiliki Batasan atas modernitas, yang maknanya bahwa kota yang identik dengan modernitas, tetapi justru bagian ini memiliki karakteristik yang sebaliknya. Istilah ini mulai dikenal semenjak akhir abad ke16. Dengan demikian konsep kota tua ini adalah aset kota yang terdiri dari bangunan, lanskap, budaya, masyarakat dengan tangible dan intangible aset-nya yang ada pada wilayah bagian kota, yang masih bisa ditemui, diidentifikasi dan dilihat.

Keberadaan kota tua ini dimungkinkan masih terabaikan, mulai dikelola atau bahkan dikelola dengan baik. Terdapat kota tertentu yang dapat mengelola dan mengembangkannya dengan baik tetapi ada juga yang masih mengabaikan aset potensial tersebut. Adapun tujuan dari jurnal ini adalah mengidentifikasi konsepsi awal tentang bagaimana sebuah kota di Indonesia, memiliki daya Tarik terhadap pemanfaatan Kota Tua sebagai aset wisata.

\section{METODE PENELITIAN}

Pada dasarnya penelitian yang dilakukan ini adalah jenis riset cepat (quick research) dengan menggunakan data sekunder sebagai data dan informasi yang digunakan, aktivitas ini merupakan preliminary research yang perlu pendalaman lebih lanjut.

\section{Teknik pengumpulan data}

Kajian ini merupakan kajian awal, sehingga teknik pengumpulan data yang digunakan adalah eksplorasi studi Pustaka untuk melengkapi berbagai informasi yang dibutuhkan.

\section{Teknik analisis}

Teknik analisis yang digunakan adalah eksploratif naratif, yakni mengeksplorasi berbagai informasi yang ada, lantas informasi ini dianalisis sedemikian rupa dan dinarasikan untuk membangun informasi awal tentang pariwisata kota tua ini.

\section{Tahapan Penelitian}

Tahapan yang dilakukan pada penelitian ini adalah mengidentifikasi dan mengeksplorasi proses yang dilakukan oleh kota Semarang dalam mengelola dan mengembangkan Kawasan kota tuanya menjadi destinasi wisata, yang akan di komparasi-kan dengan kota - kota lainnya yang melakukan hal yang sama; berikutnya, mengidentifikasi kota - kota yang memiliki potensi keberadaan Kawasan kota tua; ketiga, prasyarat apa saja yang mesti dipenuhi oleh kotanya dalam pengembangan destinasi wisata utamanya yang berbasis sejarah atau cagar budaya; keempat, Menyusun tahapan pengembangan cagar budaya benda dan tak benda; kelima, rekomendasi / konklusi akhir. 


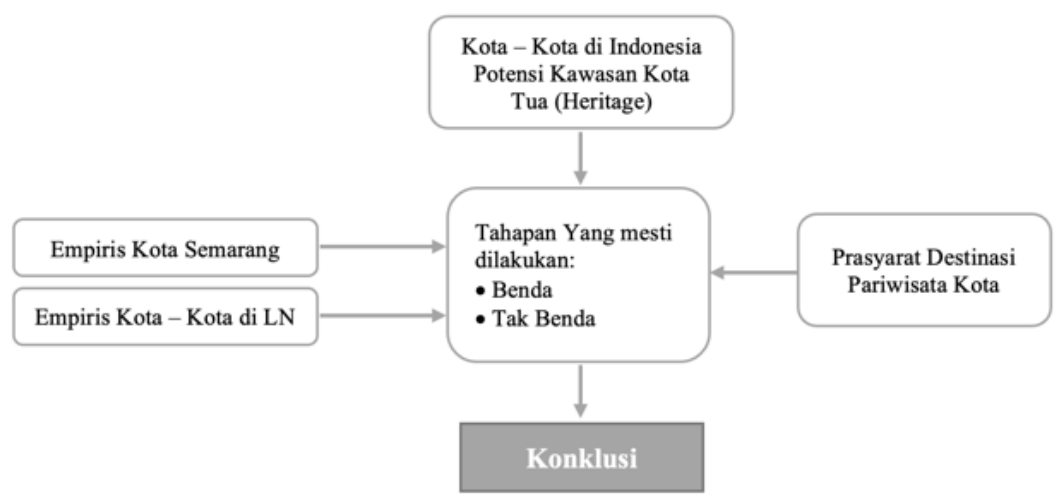

\section{HASIL DAN PEMBAHASAN \\ Benchmarking Analisis}

Bahan ini digunakan untuk bahan pijakan awal bagaimana sebuah kota memiliki aset kota tuanya dan dikelola sedemikian rupa sebagai aset wisata kota. Sebagai bahan referensi, benchmarking kota tua yang dijadikan pendalaman pada kajian ini adalah Kota Tua Semarang.

\section{Kota Tua Semarang}

Pada sejarahnya, Kawasan ini dikelilingi oleh benteng. Dengan Batasan:

Utara: Noorderwalstaat / J1. Merak

Timur: Oosterwalstraat / Jl. Cendrawasih

Selatan: Zuiderwalstraat / Jl. Kepodang

Barat: Westerwaalstraat / J1. Mpu Tantular.

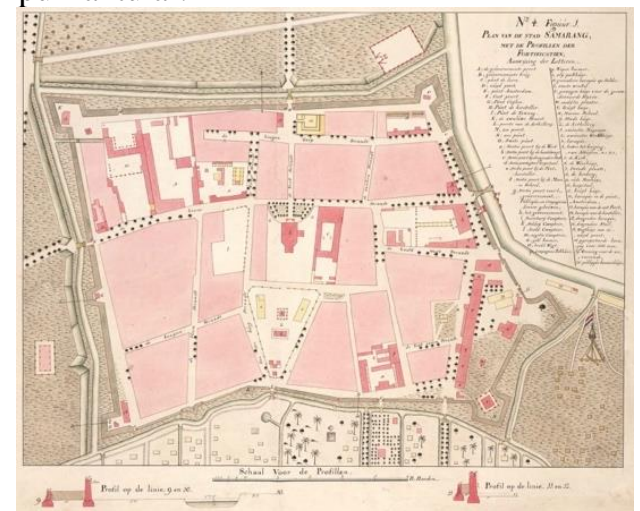

Gambar 1. Kota Lama Semarang (sumber: www.seputarsemarang.com, diunduh pada 21 Januari 2021)

Kawasan ini berada di Kelurahan Bandarharjo Kecamatan Semarang Utara, dengan luas Kawasan 40 hektar. Kawasan kota tua ini berada disisi utara kota di wilayah dataran rendah, yang acapkali juga terjadi rob/banjir karena struktur permukaan tanah yang relatif rendah. Kawasan ini berdekatan dengan pesisir laut utara atau Laut Jawa, berada dapat struktur tanah yang datar (tidak berbukit) sehingga memiliki hamparan datar yang luas.

Jumlah bangunan yang ada sebanyak 245 buah, terdiri dari 177 buah (72\%) milik pribadi dan 68 buah $(28 \%)$ milik perusahaan. Bangunan ini digunakan untuk rumah tinggal sebanyak 139 buah (56\%), bangunan kosong 19 buah $(0,7 \%)$ dan bangunan non hunian sebanyak 87 buah (35\%). Secara status, 130 buah haknya di ketahui namun masih ada 115 buah yang status hak belum diketahui. Sampai dengan saat ini sudah 105 buah bangunan yang telah dikonservasi. 


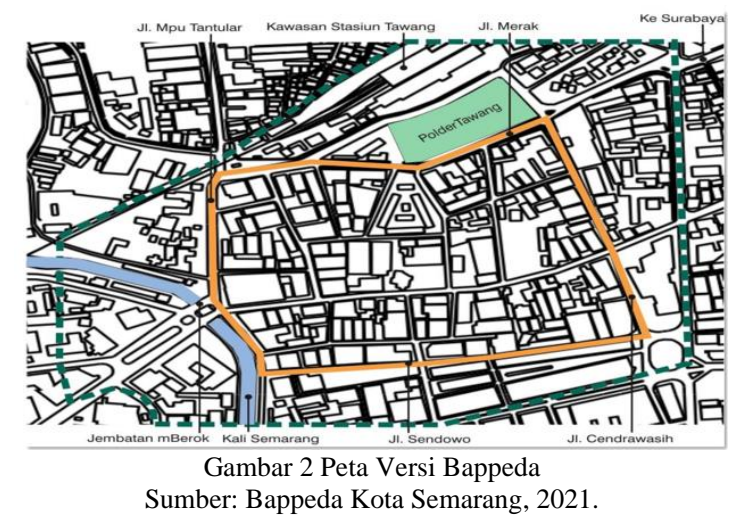

Jika akan menelusuri Kota lama Semarang, kita bisa memulai dari titik nol km tepatnya dari Kantor Pos, menemui Gedung Het Groot Huis, kantor residen Semarang era kolonial sekarang sebagai kantor keuangan, yang biasa dikenal sebagai Gedung Papak. Lantas kita menyeberangi Jembatan kali Berok, di sungai inilah pada masa itu kapal - kapal pedagang berlabuh. Di sisi timur sungai, terbentang jalan utara ke selatan yakni jalan Mpu Tantular yang merupakan batas barat dari Kota lama. Jika kita jalan ke timur, maka jalan inilah salah satu jalan utamanya, yakni jalan Letjen Suprapto, kita akan menemui Gedung tua yang digunakan Bank Mandiri Mpu Tantular, Old City 3D Art, Semarang Creative Galery dan galeri UMKM. Lantas kita menemui Gereja Blenduk, Bangunan yang digunakan Jiwa Sraya dan Taman Srigunting. Jalan Letjen Suprapto ini merupakan bagian dari jalan Anyer Panarukan $1000 \mathrm{~km}$. Kota Lama Semarang ini pada dasarnya mengadaptasi bangunan - bangunan Belanda sehingga dikenal sebagai kampung Eropa atau biasa disebut dengan De Oude stad (Kota Lama) Eiropeeshebuurt (Kampung Eropa).

\section{Kawasan kota Lama Semarang meliputi}

Beberapa bangunan tua yang ada di Kawasan ini berupa bangunan perkantoran, gereja, klenteng, termasuk pusat pemerintahan, industry serta perdagangan. Fasilitas kota yang tersedia adalah Gedung teater Marabunta (schouwburg), lantas ada pengadilan Negeri (kantor landraad), took perhiasan bergensi (N.VGoud en Zilversmederij voorheen F.M. Ohlenroth \& Co., kantor perusahaan yang mengelola perkebunan di Jawa Timur dan Jawa Tengah (terdapat 2 kantor), hotel Jansen, dan toko alat musik Seelig \& Son. Terdapat pula kantor percetakan dan penerbitan besar, serta maskapai asuransi Jiwa Hindia Belanda, yang akhirnya menjadi Kantor Asuransi Jiwa Sraya.

\section{Sejarah Revitalisasi Kawasan Kota Lama Semarang. Tahun 2000-an}

Penetapan kota lama sebagai salah satu cagar budaya di Kota Semarang yang dilindungi. Mulai terdapat penambahan elemen kota dan perbaikan fisik, seperti fasade, jalan pedestrian, ruang jalan dan street furniture (Sitompul \& Roychansyah, 2018).

Identifikasi

Mengidentifikasi bangunan cagar budaya (heritage) dan status kepemilikannya. 2011: Menyusun grand desain kota lama Semarang. 2015: Desain teknis detail (Detailed engineering design) Kota lama.

\section{Revitalisasi Tahap I (2017-2018)}

Dengan dukungan dari Kementerian PUPR, mulai dikerjakan pada tahun 2017. Telah mencapai $80 \%$ dari 116 bangunan telah mengalami revitalisasi. Gedung - Gedung cagar budaya digunakan untuk perkantoran, restoran, café, kedai kopi dan tempat wisata (Gewati, 2019).

Revitalisasi Tahap II (2019-2020)

Pembangunan museum Bundaran Bubakan dan rumah pompa di Berok. Rumah pompa yang berfungsi sebagai pengendali banjir ini, sekaligus digunakan untuk melakukan fungsi daya Tarik wisata. Berikutnya penataan jalan, di jalan Sleko yang menghubungkan antara Kota Lama dengan Kawasan Melayu. Kawasan ini juga menghubungkan dengan Kawasan pecinan dan kampung Melayu. Berikutnya penataan jalan Suari. Untuk pembangunan tahap II ini, didukung oleh Kementerian PUPR sebesar Rp 60 miliar. (TribunJateng.com, 2020) 


\section{Tata Kelola Kota Lama Semarang.} garis besar:

Mengacu dari Konsep Bappeda Kota Semarang terdapat 3 bagian Lembaga yang terlibat secara

1) Pemerintah Kota Semarang, yang memiliki peranan dalam Menyusun dan menyiapkan regulasi tentang pengelolaan Kota Tua. Pemerintah ini nantinya secara teknis akan dilakukan oleh Badan Pengelola Kawasan Kota Lama Semarang. Lembaga ini nantinya sebagai fungsi Kota Lama Management Board.

2) Pemilik bangunan. Partisipasi dan rasa memiliki para pemilik tanah dan bangunan ini tentunya memiliki peran yang besar.

3) Investor, merekalah yang mempunyai sumber daya ekonomi yang mestinya bersedia menginvestasikan aktivitas ekonominya di Kawasan Kota Lama Semarang.

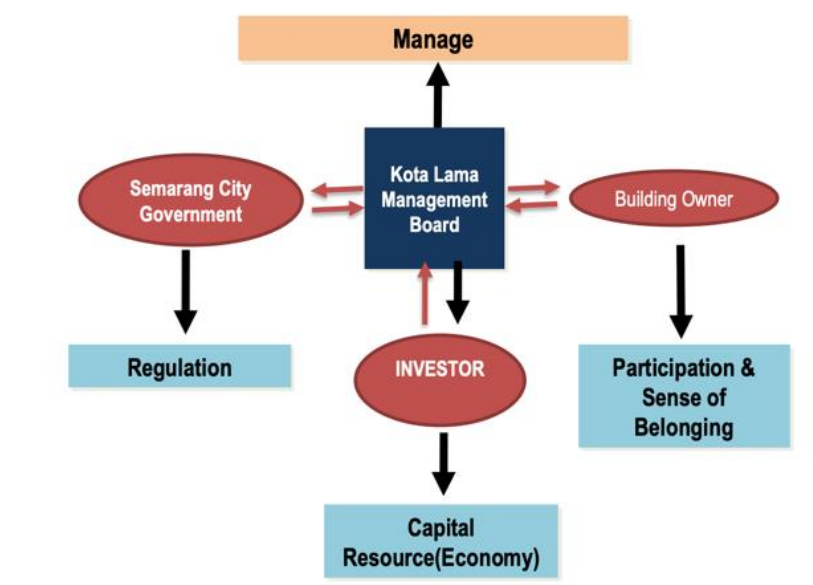

(sumber: Bappeda Kota Semarang, https://www.connective-cities.net, 2021)

\section{Landasan hukum.}

1) Keputusan Walikota Semarang No. 646/50 1992 tentang Konservasi Bangunan - bangunan Kuno/Bersejarah di Wilayah Kodya Semarang.

2) Perda No. 2 Tahun 1992 tentang Rencana Umum Tata Ruang Kota (RUTRK).

3) Perda No. 8 Tahun 2003 tentang RTBL Kawasan Kota Lama Semarang.

4) Perda No. 14 Tahun 2011 tentang Rencana Tata Ruang Wilayah.

\section{Para Pemangku Kepentingan. \\ Pemerintah}

Pemerintah daerah yang memiliki kewenangan terhadap Kawasan kota lama adalah Pemerintah Kota Semarang, di mana Walikota membentuk Badan, yakni Badan Pengelola Kawasan Kota Lama Semarang (BPK2L). Beberapa fungsi yang dijalankan adalah: pengawasan terhadap Gedung - Gedung, inventarisasi bangunan yang diabaikan dan mengajak secara persuasif para pemilik bangunan untuk memanfaatkan Kembali aset tersebut, layanan rekomendasi perijinan, penyediaan informasi dan data tentang Kawasan kota lama. Selain badan ini, maka SKPD yang yang dilibatkan pula adalah Dinas Kebudayaan \& Pariwisata, Dinas Penataan Ruang Kota, dan Bappeda (Noor S, 2019).

\section{Masyarakat}

Berdasar penelitian Mangihut \& Khadiyanto (2014), partisipasi masyarakat dalam pengelolaan kota lama Semarang belum dilakukan secara optimal, hal ini disebabkan oleh tingkat pengetahuan dan kesadaran masyarakat, tingkat penghasilan yang masih rendah dan pola kerja yang dilakukan. Penelitian ini memperoleh informasi bahwa para Kepala Keluarga rata - rata hanya lulusan SD, rata - rata mereka sebagai pekerja dengan tingkat pendapatan hanya sebatas UMR dan kepemilikan bangunan tempat tinggalnya juga tidak jelas, walaupun mereka telah tinggal berpuluh puluh tahun.

Organisasi Nirlaba. (1) OASE (Oudestad Art and Culture Semarang) merupakan salah satu organisasi yang memiliki peran dalam pengelolaan Kawasan kota lama Semarang. Organisasi ini juga melakukan pendampingan pada masyarakat yang tinggal di Kawasan Kota Lama Semarang. (2) Asosiasi Masyarakat Bangun Oude Stad (AMBO)

Dibentuk pada tahun 2012. Baru pada tahun 2017, organisasi ini memiliki aktivitas yang lebih permanen, dengan mengadakan beberapa festival di kota lama. (3) Oen Semarang Foundation, Bersama 
dengan Asosiasi Masyarakat Mbangun Oude Stad melakukan beberapa kali festival, dimana event Festival Kota Lama Semarang telah dilakukan mulai 2012 - 2019.

Bahan Pembelajaran yang diperoleh:

1) Mengambil figur yang tepat untuk pengelola BPK2L beserta SDM yang ada di dalamnya.

2) Pendanaan yang tepat. Pemerintah Kota Semarang memiliki keterbatasan dalam pendanaan, sehingga dukungan dari Pemerintah Pusat sangat dibutuhkan. Dikombinasi dengan perencanaan yang baik, komunikasi kepada pemerintah pusat.

3) Infrastruktur yang baik sebagai kunci. Jalan yang baik, drainase akan mendorong aktivitas ekonomi di Kawasan ini.

4) Peran keterlibatan komunitas (community).

Potensi Kota Lama yang terdapat di Berbagai Kota di Indonesia.

Beberapa kota di Indonesia memiliki Kawasan kota lama yang menjadi Kawasan cagar budaya dan berpeluang untuk menjadi aset destinasi pariwisata. Kota - kota ini di antaranya adalah:

\begin{tabular}{|c|c|c|c|}
\hline No & Kota & Uraian & Kondisi \\
\hline 1. & Jakarta & & $\begin{array}{l}\text { Sudah di } \\
\text { revitalisasi }\end{array}$ \\
\hline 2. & Bandung & $\begin{array}{c}\text { Kawasan Braga, Jl. Asia } \\
\text { Afrika }\end{array}$ & $\begin{array}{l}\text { Sudah di } \\
\text { revitalisasi }\end{array}$ \\
\hline 3. & Cirebon & $\begin{array}{c}\text { Kawasan Kota Tua } \\
\text { Lemahwungkuk } \\
\text { Kawasan Jamblang. } \\
\text { Pecinan. }\end{array}$ & Belum. \\
\hline 4. & Surabaya & $\begin{array}{l}\text { J1. Kalimalang, J1. } \\
\text { Veteran \& J1 Karet }\end{array}$ & Belum optimal \\
\hline 5. & Yogyakarta & $\begin{array}{l}\text { Benteng Vredenburg, } \\
\text { Kantor Pos Besar, Bank } \\
\text { Indonesia, Gedung BNI, } \\
\text { Gedung Agung, Gedung } \\
\text { AMS (Algemene } \\
\text { Middelbare School) } \\
\text { Normalschool dll. } \\
\text { Termasuk Kawasan Kota } \\
\text { Gedhe }\end{array}$ & $\begin{array}{c}\text { Sudah } \\
\text { direvitalisasi. } \\
\text { Terletak } \\
\text { tersebar, } \\
\text { bukan pada } \\
\text { satu Kawasan. }\end{array}$ \\
\hline 6. & Medan & $\begin{array}{l}\text { Masjid Raya Al-Mahsun, } \\
\text { Istana Maimun, } \\
\text { Kawasan Kesawan, } \\
\text { warenhuis, Gedung } \\
\text { London Sumatera } \\
\text { (Lonsum), Gedung BI } \\
\text { Medan, Kantor Pos Besar } \\
\text { Medan, Tjong A Fie } \\
\text { Mansion, Gedung } \\
\text { Balaikota Lama Medan }\end{array}$ & $\begin{array}{c}\text { Ada beberapa } \\
\text { bangunan } \\
\text { yang terjaga } \\
\text { dengan baik. } \\
\text { Ada beberapa } \\
\text { yang } \\
\text { kondisinya } \\
\text { buruk. }\end{array}$ \\
\hline 7. & Palembang & $\begin{array}{c}\text { Kawasan Sekanak } \\
\text { Kampung Arab }\end{array}$ & \\
\hline $\begin{array}{l}8 . \\
9 .\end{array}$ & $\begin{array}{c}\text { Padang } \\
\text { Singkawang }\end{array}$ & Pengaruh Hindia Belanda & \\
\hline 10. & Mataram & Kawasan Ampenan & \\
\hline 11. & Salatiga & Jl. Diponegoro & \\
\hline 12. & Solo & Kampung Batik Laweyan & \\
\hline 13. & Kendari & $\begin{array}{c}\text { Area sisi utara Jembatan } \\
\text { Oprit }\end{array}$ & $\begin{array}{l}\text { Proses } \\
\text { pengemban } \\
\text { gan }\end{array}$ \\
\hline 14. & Makasar & $\begin{array}{c}\text { Kec. Waju, } \\
\text { Ujungpandang, \& Mariso } \\
\text { (www.koran.tempo.co.id) }\end{array}$ & $\begin{array}{l}\text { Perlu } \\
\text { pengembang } \\
\text { an lebih } \\
\text { lanjut }\end{array}$ \\
\hline 15. & Magelang & $\begin{array}{c}\text { Kampung Tua Kwarasan, } \\
\text { Museum Jendral } \\
\text { Sudirman } \\
\text { (www.kompas.com) }\end{array}$ & $\begin{array}{l}\text { Belum } \\
\text { dikembang } \\
\text { kan }\end{array}$ \\
\hline 16. & Bogor & $\begin{array}{l}\text { Kawasan Pecinan } \\
\text { Suryakencana, Jalan } \\
\text { utama Bogor }\end{array}$ & $\begin{array}{c}\text { Perlu } \\
\text { pengembang } \\
\text { an }\end{array}$ \\
\hline 17. & Pontianak & $\begin{array}{c}\text { Pelabuhan Seng Hie, } \\
\text { Pasar Tengah, Masjid } \\
\text { jami, SDN } 14 \text { Pontianak, }\end{array}$ & $\begin{array}{c}\text { Perlu } \\
\text { Pengembang } \\
\text { an }\end{array}$ \\
\hline
\end{tabular}




\begin{tabular}{cccc}
\hline No & Kota & Uraian & Kondisi \\
\hline \multicolumn{4}{c}{ Kebok Sajoek. } \\
18 & Barus, & (www.kumparan.com) \\
& Desa Labu Tua, Pesisir \\
& Tapanuli & Barus \\
\hline \multicolumn{3}{c}{ Sengah } & \\
\hline \multicolumn{3}{c}{ Sumber: disarikan dari berbagai data, 2021 }
\end{tabular}

Sementara itu Kementarian PUPR dalam dokumen kota pusaka telah mengkompilasi 51 kota di berbagai Propinsi di Indonesia yang Bersama - sama berupaya melakukan pelestarian terhadap bangunan cagar budaya (www.sim.pu.go.id, 2021)

Kajian yang dilakukan Ismail (2016) Menemukan konsepsi bahwa mempertahankan bangunan cagar budaya akan berhasil jika hal ini memenuhi fungsi layanan bagi generasi muda, jika generasi muda tak membutuhkannya maka mereka akan merasa tidak membutuhkan untuk ikut serta menyelamatkan bangunan ini. Generasi mud aini pada umumnya pergi ke kota untuk berbelanja dan makan. Sehingga untuk menyediakan struktur bangunan tersebut, tentunya tidak perlu membangun yang baru, tetapi memanfaatkan bangunan - bangunan untuk tujuan yang sama. Sehingga dapat mempertahankan bentuk asli bangunan tersebut, tetapi mengubah aktivitas didalamnya.

Cara terbaik menjaga kelestarian bangunan menurut hasil kajian ini adalah dengan mengubah aktivitas pada bangunan tersebut tetapi tetap mempertahankan bentuk aslinya. Otoritas Pembangunan Daerah Iskandar (Johor Bahru) beruapaya melakukan hal tersebut melalui gelar inisiatif warisan dan budaya cagar budaya, dokumentasi semua warisan dan aktivitas budaya, dan meningkatkan permintaan akan warisan dan pariwisata budaya. Sampai akhirnya bisa dipastikan cagar budaya yang ada di Kota Johor Baru menjadi salah satu bagian Situs Warisan Dunia Unesco.

Temuan Pratama (2017) berkaitan dengan keberadaan Kota Tua Jakarta dijelaskan bahwa identitas kota tua Jakarta terbentuk atas keberadaan Taman Fatahillah, Museum Sejarah Jakarta, dan bangunan bangunan tua di Kawasan Taman Fatahillah. Identitas ini dibentuk atas 3 atribut, yakni (1) keberadaan ruang publik yang bertemakan sejarah, (2) bangunan tua dan (3) tempat edukasi dengan konten kesejarahan. Brand image yang dihasilkan adalah The Most Memorable Place of Batavia.

Sementara itu Kepala Unit Pengelola Kawasan (UPK) Kota Tua Jakarta, Novianto Setio, mengembangkan pariwisata Kota Tua ini melalui Event di Kota Tua, seperti festival tempo dulu, festival kuliner jadul, pembinaan karakter komunitas. Pengembangan karakter Kawasan juga dilakukan seperti pengembangan Kawasan Glodok sebagai kampung etnis China, Pekojan kampung Arab, dan Kawasan pesisir Sunda Kelapa. Selain itu, pengetahuan pemilik / pengelola terhadap cagar budaya memang semestinya dikembangkan, pemahaman atas pentingnya konservasi mesti dibangun (Santoso, 2019). Salah satu PR Kota Tua Jakarta adalah belum tersedianya makanan atau oleh - oleh khas yang menjadi daya Tarik wisatawan.

Sementara Amiluruh Soeroso, Pengamat Kebijakan Publik UGM (Santoso, 2019) menyatakan bahwa keunikan yang ditonjolkan Yogya adalah pada nilai sejarah, sosial budaya, dan arsitektural yang dimiliki oleh setiap Kawasan. Ketika di-komparasi-kan dengan keberadaan Kota Tua George Town Penang, keberadaan kota tua tersebut dipersepsikan mampu memberi dampak positif pada bisnis lokal, konservasi dan restorasi bangunan cagar budaya, dan mampu mendorong kesejahteraan umum bagi penduduk George Town. Banyak responden setuju bahwa restorasi dan konservasi bangunan cagar budaya merupakan warisan yang mesti dijaga. Namun separuh responden memandang aktivitas wisata bisa mengancam nilai nilai cagar budaya. Hal yang sama terjadi di berbagai tempat bahwa para pemangku kepentingan keterlibatannya masih rendah dalam perencanaan dan pengembangan (Omar, 2013).

Sementara itu riset yang dilakukan Khodeir, Aly, \& Tarek (2016), aplikasi keberlanjutan retrofit dari bangunan cagar budaya di Mesir dengan mengintegrasikan alat HBIM (heritage Building Informasi Modeling / Permodelan Informasi Bangunan Cagar Budaya) ditemukan bahwa Permodelan HBIM sebagai alat komputasi ini dapat dipergunakan sebagai kumpulan data informasi yang komprehensif, khususnya terkait dengan pemugaran bangunan. Temuan riset ini adalah memberikan kerangka kerja yang berguna untuk retrofit bangunan warisan yang berkelanjutan pada konteks Mesir. Di mana kerangka kerjanya meliputi: inisiasi, perencanaan, pelaksanaan, pemantauan dan penilaian. Model HBIM ini tentunya menarik sebagai salah satu referensi.

\section{Prasyarat pengembangan destinasi}

Firmansyah, Dirjen Pengembangan Destinasi pariwisata (dalam Mutya, 2013) menyatakan terdapat 4 unsur menjadi suatu destinasi layak sebagai destinasi wisata, yakni:

(1) Daya Tarik, di mana daya Tarik ini bisa dibuat atau yang telah ada di destinasi tersebut. Secara umum Kawasan cagar budaya memiliki daya Tarik yang telah ada, yakni keunikan arsitektural bangunan. 
Namun pada kondisi yang kemungkinan buruk, mulai rapuh, kotor dan tak layak kunjung. Tak layak kunjung karena berbahaya, atau berdebu dan tak aman. Sehingga perlu adanya renovasi / revitalisasi tanpa merusak struktur dan arsitektur aslinya.

(2) Aksesibilitas. Destinasi mesti memiliki transportasi dan sarana jalan yang baik. Pada umumnya Kawasan kota tua, memiliki akses jalan yang baik menuju ke Kawasan tersebut. Namun sarana jalan ini justru buruk di destinasinya, umumnya kualitas yang buruk, gorong - gorong yang jelek atau tidak ada, bahkan pedestriannya pun juga demikian. Sehingga penataan Kembali akses ke dan di Kawasan kota tua mesti dilakukan.

(3) Infrastruktur fasilitas dan penunjang kebutuhan wisatawan. Bisa dilakukan oleh hotel, restoran, ASITA, PHRI ataupun pihak lainnya.

Sedangkan Rai Utama, mengidentifikasi aspek - aspek:

(1) Aspek daya Tarik destinasi. Bisa alam (memungkinkan bangunan), masyarakat maupun budaya.

(2) Transportasi / aksesibilitas.

(3) Akses fasilitas utama dan pendukung.

(4) Aspek kelembagaan.

(Utama \& Rai, 2013) melanjutkan bahwa untuk mencapai 4 hal di atas juga mesti memperhatikan,

(1) Penataan sentra bisnis masyarakat local. Seperti pasar malam tradisional, makanan tradisional, pagelaran seni, Spa dan sejenisnya yang melayani terapi dan relaksasi.

(2) Penataan penginapan, hotel dan sejenisnya, yang memungkinkan diarahkan ke sub urban agar mengurangi ke-crowded-an kota.

(3) Penataan daerah ataraksi wisata baik yang alami ataupun buatan diarahkan pada Kawasan rural / countryside.

Berbagai modal kota atau ikon kota yang memungkinkan dijadikan destinasi wisata yang menarik, seperti pusat peribadatan, alun alun, kantor balai kota, monument kota, museum, jalan - jalan tertentu yang menjadi ikon atau area area tertentu yang atas inovasi dan kreatifitas pengelola kota bisa menjadi destinasi yang layak dinikmati (Afandi, Indrawan, \& Ratnawardhani, 2019).

\section{Tahapan Yang Disiapkan oleh Kota}

Beberapa pentahapan yang mesti disiapkan kota dalam pengembangan aset kota tuanya sebagai destinasi wisata adalah:

1. Penjajakan awal. Mengidentifikasi dan mengeksplorasi apakah kota memiliki potensi aset wisata kota yang layak dan potensial untuk dikembangkan.

2. Identifikasi sumber daya yang tersedia. Terdiri: (a) sumber daya cagar budaya benda dan tak benda, tak benda ini idealnya tidak diabaikan; (b) Daftar cagar budaya; (c) Rencana tata ruang tersedia dan posisi cagar budaya; (d) Peraturan sampai dengan peraturan di tingkat daerah berkaitan dengan cagar budaya; ( e ) kebutuhan sumber daya lainnya yang berkaitan.

3. Inisiasi dengan pemangku kepentingan. Aktivitas ini cukup berat jika hanya bertumpu pada pemerintah (government centered). Kolaborasi dengan para pemangku menjadi kekuatan yang Tangguh. Pemerintah Daerah, Pemerintah Pusat, Masyarakat local, komunitas, swasta / Lembaga bisnis, bahkan Lembaga dunia (UNESCO, dan lainnya) semuanya memiliki peran masing - masing dalam upaya pengembangan.

4. Mengembangkan visi dan misi yang jelas dalam upaya pengembangan kota tua, bukan hanya sekedar latah mengikuti kota lainnya. Setiap kota memiliki potensi dan kearifan lokal, yang layak untuk dikembangkan. Visi ini bukan hanya sekedar dokumen tertulis, lebih dari itu menjadi visi dan spirit Bersama bagi para pemangku kepentingan.

5. Benchmarking pada kota lain, yang dinilai memiliki kemiripan identitas budaya / latar belakang, kota yang memiliki aset cagar budaya tersebut dan mampu mengelolanya dengan baik.

6. Penetapan Gedung ataupun Kawasan cagar budaya.

7. Menyusun dokumen perencanaan sekaligus rencana aksi, baik aktivitas tahunan ataupun multi tahunan. Rencana ini sebenarnya bukan hanya aktivitas revitalisasi asset benda saja (bangunan) tetapi seharusnya juga asset tak benda.

8. Penjajakan mekanisme dan sistem pendanaan yang digunakan, sehingga tidak hanya membebankan pada APBD, lebih ideal lagi ternyata meminimkan pendanaan melalui sumber APBD.

9. Penyiapan dan pembentukan badan otoritas jika dibutuhkan. Perlu disesuaikan dengan tingkat kebutuhan yang diperlukan.

10. Revitalisasi. Revitalisasi ini bisa dilakukan dalam beberapa tahap / beberapa tahun, dengan pentahapan yang runtut. 
11. Pengembangan tata Kelola dan pemberdayaan masyarakat Kawasan kota tua, sebagai aset tak benda.

12. Upaya perolehan benefit atas keberadaan aset cagar budaya tersebut, yang salah satu fungsi utamanya untuk sumber pendanaan operasional tata Kelola Kawasan cagar budaya, tidak menampik bahwa kesempatan untuk mengembangkan sebagai Kawasan ekonomi juga bisa dilakukan, karena salah satu urat nadi juga bersumber dari aktivitas ini, tanpa mengabaikan nilai - nilai keberlanjutan dan kelestarian aset benda dan tak benda.

Berikutnya untuk pengembangan dan pengelolaan warisan budaya tak benda (intangible heritage) yang dapat berupa kuliner (masakan, minuman, oleh - oleh / makanan khas), seni pertunjukan, kerajinan tangan, dan ritual (upacara adat). Adalah:

1) Inisiasi dengan masyarakat lokal / setempat.

2) Identifikasi intangible asset yang masih ada dan menelusur yang berkaitan dengan hal tersebut.

3) Perlu adanya pendampingan dan pemberdayaan oleh NGO terlebih lagi bila masyarakat nya memiliki tingkat Pendidikan yang belum terlalu tinggi, meningkatkan kesadaran mereka menariknya menjaga nilai - nilai lokal, aset warisan budaya tak benda ini dan nilai sosial ekonominya.

4) Dorongan dan dukungan dari Perguruan Tinggi, sekolah kejuruan ataupun Lembaga terkait lainnya guna peningkatan kualitas nilai warisan budaya tak benda ini. Misal bagaimana makanan resep masa lalu, memenuhi kaidah higienitas, memenuhi syarat gizi dan standar - standar lainnya. Dimungkinkan pula sampai dengan sertifikasi halal, bila dibutuhkan.

5) Upaya memulai adanya event, festival dan bentuk promosi lainnya.

6) Mensinergikan nilai menjaga warisan budaya dengan konsep ekonomi agar memiliki nilai tambah kesejahteraan bagi masyarakat, walaupun ini bukan satu - satunya tujuan.

7) Membranding warisan budaya tak benda sebagai IKON KOTA.

Langkah - Langkah tersebut diatas merupakan raw model awal kebijakan public yang bisa diadaptasi kota dalam pengelolaan kotanya secara komprehensif, tentunya tetap mengacu pada Undang Undang yang berlaku.

\section{KESIMPULAN}

Penelitian ini mengidentifikasi pentahapan yang mesti dilakukan pemerintah, yang memungkinkan untuk dimodifikasi sedemikian rupa menyesuaikan dengan kondisi empiris lapang. Karena karakteristik setiap kota memiliki keunikan, dan kearifan lokal yang berbeda. Sehingga perlu penyesuaian dan agar presisi. Termasuk pula dalam pentahapan pengembangan warisan budaya tak benda (intangible). Pentahapan yang direkomendasikan ini akan lebih menarik bila diuji melalui serangkaian FGD para ahli maupun praktisi dibidang cagar budaya.

\section{UCAPAN TERIMA KASIH}

Terimakasih pada semua pihak yang tidak bisa penulis sebutkan satu persatu, semoga kajian ini bisa ditindak lanjuti dengan kajian yang lebih mendalam dan komprehensif.

\section{DAFTAR PUSTAKA}

Afandi, A., Indrawan, A. K., \& Ratnawardhani, E. A. (2019). Analisis Model Penilaian Kota Ideal Destinasi Wisata. Barista: Jurnal Kajian Bahasa dan Pariwisata, 6(1), 1-7.

Dixit, S. K. (2020). Tourism in Asian Cities. Routledge.

Gewati, M. (2019, Agustus 26). Revitalisasi Tahap 1 Kelar, Wajah Baru Kota Lama Semarang Mulai Nampak. Retrieved from https://regional.kompas.com/

Indriani, A. (2017, April). Retrieved Maret 29, 2021, from Pelestarian Cagar Budaya Terbentur Ketidaksiapan Aturan Pelaksana: www.mediaindonesia.com

Ismail, W. H. (2016). Young visitors in the city: Their perceptions of heritage buildings. Procedia-Social and Behavioral Sciences 234, 470-477.

Khodeir, L. M., Aly, D., \& Tarek, S. (2016). Integrating HBIM (Heritage Building Information Modeling) tools in the application of sustainable retrofitting of heritage buildings in Egypt. Procedia Environmental Sciences 34 , 258-270.

Mangihut, T. E., \& Khadiyanto, P. (2014). Partisipasi Masyarakat dalam Pengelolaan Kawasan Kota Lama Semarang. Jurnal Ruang, 2(2), 101-110.

Mutya. (2013). 5 Syarat Suatu Tempat Bisa Jadi Destinasi Wisata di Indonesia. lifestyle.okezone. Retrieved from www.lifestyle.okezone.com 
Noor S, F. A. (2019). Peran Stakeholder Dalam Pengelolaan Kawasan Kota Lama Semarang, Jawa Tengah. Repository STP Bandung.

Nuriata. (2014). Paket Wisata, Penyusunan Produk dan Penghitungan Harga. Bandung: Alfabeta.

Omar, S. I. (2013). George Town, Penang as a world heritage site: The stakeholders' perceptions. ProcediaSocial and Behavioral Sciences 91, 88-96.

Pratama, O. (2017). Evaluasi Kesesuaian Branding "Manhattan of Asia” dan Identitas Kota Tua Jakarta. Prosiding Industrial Research Workshop and National Seminar, 8, pp. 143-150.

Santoso, Y. I. (2019). Mengembangkan potensi pariwisata di Kota Tua. https://lifestyle.kontan.co.id/.

Seakhoa-King, A. A. (2020). Tourism Destination Quality: Attributes and Dimensions. Emerald Group Publishing.

Sitompul, C. M., \& Roychansyah, M. S. (2018). Identifikasi Perkembangan Morfologi Kotalama Semarang. Teтu Ilmiah Ikatan Peneliti Lingkungan Binaan Indonesia (IPLBI), (pp. 7-13). Semarang.

TribunJateng.com. (2020, Juli 20). Retrieved from Revitalisasi Kota Lama Semarang Tahap Dua Ditargetkan Rampung Akhir Desember 2020: https://jateng.tribunnews.com/

Utama, I. G., \& Rai, G. B. (2013). Pengembangan wisata kota sebagai pariwisata masa depan indonesia. Seminar Nasional UNHI. Denpasar. 